UDK: 005.936.5

DOI: https://doi.org/10.24867/04HZ03Trbulin

\title{
ENERGETSKE UŠTEDE OSTVARENE PRILIKOM UPOTREBE OTPADNOG STAKLA KAO SEKUNDARNE SIROVINE ZA DOBIJANJE KERAMIČKIH PROIZVODA
}

\section{ENERGY SAVINGS ACHIEVED WHEN USING WASTE GLASS AS A SECONDARY RAW MATERIAL FLOW FOR OBTAINING CERAMIC PRODUCTS}

\author{
Milan Trbulin, Zorica Mirosavljević, Dragana Štrbac, Fakultet tehničkih nauka, Novi Sad
}

\section{Oblast - INŽENJERSTVO ŽIVOTNE SREDINE}

Kratak sadržaj - U ovom radu, ispitivana je mogućnost upotrebe otpadnog stakla kao sekundarne sirovine za ostvarivanje potencijalnih energetskih ušteda u industriji građevinskog materijala na teritoriji Vojvodine. Rezultati ukazuju na to da su energetske uštede moguće zamenom osnovne sirovine( gline) sa izvesnom količinom otpadnog stakla. Prilikom kombinovanja različitih masenih odnosa, došlo se do zaključka da se potencijalno najveće energetske uštede ostvaruju pri masenom odnosu gline $i$ stakla od 50:50\%.

Abstract - This paper examines the possibility of using waste glass as a secondary raw material for achieving potential energy savings in the construction materials industry in Vojvodina. The results show that energy savings can be achieved by replacing the basic raw material (clay) with a certain quantity of waste glass. When combining different mass ratios, it was concluded that potentially the highest energy savings are achieved with a mass ratio of clay and glass of 50: $50 \%$.

Ključne reči: opeka, keramički proizvodi, glina, staklo, energetske uštede.

\section{UVOD}

Upotreba stakla u cilju smanjenja potrošnje energije je danas, jedna veoma zahtevna oblast, koja privlači sve više pažnje, kako na lokalnom tako i na globalnom nivou. Moderno društvo proizvodi značajne količine stakla i javlja se jedan jako bitan problem, kako efikasno iskoristiti otpadno staklo i smanjiti količinu energije koja se koristi.

Procesi reciklaže postali su sve značajniji, uglavnom zbog povećanja generisanja otpada i sve veće pažnje usmerene ka zaštiti životne sredine. U savremenom društvu poboljšanje životnog standarda i tehnološkog razvoja dovelo je do značajnog rasta u potošnji stakla.

Tendencija za ponovnom upotrebom otpadnog stakla dovela je do toga da se poslednjih godina ono sve više pojavljuje kao alternativa tradicionalnim sirovinskim materijalima u kermičkim proizvodima. Korišćenje otpadnog stakla u proizvodnji građevinskog materijala je veoma pogodno, jer može da smanji potrošnju prirodnih resursa i da smanji troškove odlaganja otpada, štiteći životnu sredinu od negativnih uticaja.

\section{NAPOMENA:}

Ovaj rad proistekao je iz master rada čiji mentor je bila dr Dragana Štrbac, vanr.prof.
Cilj rada jeste da se prikažu metode i procesi iskorišćenja otpadnog stakla sa stanovišta uštede energije, koji se mogu naći u literaturi $\mathrm{i}$ da se proceni primena jednog ovakvog iskorišćenja otpadnog stakla na primeru ciglane u Vojvodini. Različiti pristupi donose različite rezultate, dok svi teže zajedničkim ciljevima, maksimalnom smanjenju upotrebe osnovnih sirovina, maksimalnom iskorišćenju otpadnog stakla i očuvanju životne sredine.

\section{OTPADNO STAKLO KAO SEKUNDARNA SIROVINA ZA PROIZVODNJU OPEKE OD GLINE}

Otpadno staklo je otpadni materijal koji ima veliki potencijal u industiji opeke. Kao aditiv za opeku, staklo se ponaša kao poseban tok zahvaljujući sadržaju natrijumoksida $\left(\mathrm{Na}_{2} \mathrm{O}\right)$ i njegovoj nekristalnoj strukturi, zbog čega se smanjuje temperaturu pečenja opeke. Pored toga, povećana staklena faza u gotovoj opeci ima potencijal za poboljšanje kako strukturnih osobina tako i izdržljivosti.

\subsection{Sirovinski materijali-Otpadno staklo}

Staklo koje se najčešće koristi u testovima je jedno od otpadnih produkata koji ostane nakon što se oslobodi metalnih ostataka i stakla koje je jako lošeg kvaliteta iz nusprodukata insineracije. Najčešće se koristi 120 stepena mešavina, koja je produkt mešavine šarenog stakla, šljake, keramike i kamena. Kod mešavina stakla spojenih sa glinom, fino staklo se ponaša kao tok koji smanjuje temperaturu pečenja. Hemijska analiza ostataka koji sadrže velike količine stakla data je u tabeli 1 .

Tabela 1. Hemijska analiza otpadnog stakla koje se koristi u mešavinama gline i stakla [5]

\begin{tabular}{ll} 
Oksid & \multicolumn{1}{|c}{$\begin{array}{c}\text { Procenat sadržaja } \\
(\%)\end{array}$} \\
\hline $\mathrm{SiO}_{2}$ & 69.3 \\
\hline $\mathbf{A l}_{2} \mathbf{O}_{3}$ & 1.7 \\
$\mathrm{Fe}_{2} \mathbf{O}_{3}$ & 0.9 \\
$\mathrm{Na}_{2} \mathbf{O}_{3}$ & 13.9 \\
\hline $\mathbf{K}_{\mathbf{2}} \mathbf{O}$ & 0.6 \\
\hline $\mathbf{C a O}$ & 10.0 \\
\hline $\mathbf{M g O}$ & 0.4 \\
\hline Губици при паљењу (LOI) & 1.3 \\
\hline
\end{tabular}

\subsection{Materijali i metode}

Glina se najčešće uzima iz lokalnog područja gde se proizvodi opeka, radi smanjenja troškova transporta i uticaja na životnu sredinu. Hemijska analiza gline i 
otpadnog stakla, u većini slučajeva vrši se koristeći $X$ zrake. Otpadno staklo se lomi dok se ne dobije odgovarajuća struktura. Test distribucije veličine čestica anjčesše se radi upotrebom sita za granulometrijsku separaciju, a sprovodi se koristeći Sieve (Sieve - standardizovana metoda za analizu veličine čestica prema ASTM specifikacijama).

Kako bi se uporedile različite opeke svaki primerak se meša u posebnim porcelanskim posudama. Mešanje se radi obezbeđivanja homogenosti uzoraka. Po potrebi, dodaje se voda, a zatim se vrši proces mešanja kako bi se dobila odgovarajuća smesa. Opeke se prave koristeći kalup sa manuelnim oblikovanjem i pritiskanjem. One se suše, nakon čega se taj postupak ponavlja ali na većim temperaturama kako bi se uklonila preostala voda. Uzorci se zatim peku na standardnim temperaturama od 900, 950 i 1000 stepeni Celzijusovih.

Vreme potrebno da se postigne odgovarajuća temperatura varira u zavisnosti od kvaliteta peći za pečenje u kojoj su primerci držani.

Skupljanje se meri direktnim merenjem dužine primerka pre i posle pečenja. Linearno skupljanje i ukupno linearno skupljanje se mere i upoređuju sa dužinom linearnog skupljanja prema standardu ASTM C326-09. Metoda ASTM C373-14a se koristi da se odredi apsorpcija vode, gustina, očigledna gustina i očigledna poroznost.

Kompresiva snaga primeraka određuje se prema ASTM C773-88. Sva testiranja se vrše na više od deset primeraka.

Pored opisane metode za dobijanej opeke, tzv. standardno pečenje, postoje još i cementiranje i geopolimerizacija.

Metoda cementiranja ne zahteva upotrebu peći za pečenje, već se oslanja na osobine cementiranja koje potiču od samih materijala ili od drugih dodatih materijala.

Geopolimerizacija je tehnologija koja se oslanja na hemijsku reakciju amorfnog silicijuma i čvrstih čestica bogatih aluminijumom sa visoko alkalnim rastvorom na sobnoj ili malo povišenoj temperaturi usled čega bi se formirali amorfni ili polukristalni aluminosilikatni neorganski polimeri ili geopolimeri.

\subsection{Staklo kao sirovinski materijal u keramici}

Slomljeno staklo smanjuje potrebu za vodom, ubrzava sušenje i smanjuje skupljanje [1]. Zatim, na temperaturama od 1700 do 1850 stepeni Celzijusovih, staklo se može sjediniti bez uticaja na osnovnu sirovinu komada, formirajući „, lepak“ koji drži komad keramike zajedno. Funkcija glinovitog dela je da obezbedi obradljivost, da olakša formiranje na sobnim temperaturama i da zadrži oblik tokom procesa sjedinjavanja.

Staklo može biti u granularnoj ili u praškastoj formi, ali to neće u značajnoj meri uticati na obradljivost. Takođe, brzina procesa je ograničena brzinom kojom toplota dolazi do uzorka stakla ili keramike.

Korišćenjem otpadnog stakla zamenjuje se određena količina feldspara. Dodavanjem stakla dolazi do povećanja prečnika čestice a samim tim i do poboljšanja u brušenju porcelanskih proizvoda. Poboljšava se mehanička otpornost i dolazi do mikrosturkturnih modifikacija koje poboljšavaju sveukupnu otpornost na naprezanje [4]. Temperatura na kojoj se peku proizvodi se usled prisustva otpadnog stakla smanjuje.

\section{ENERGETSKE UŠTEDE PRILIKOM UPOTREBE OTPADNOG STAKLA U PROIZVODNJI KERAMIČKIH PROIZVODA}

Proizvodnja opeke je energetski veoma zahtevan i intenzivan proces. Zbog visoke potrošnje energije, aditivi se često koriste kako bi se smanjila neophodna temperatura za dobijanje opeke. Aditivi koji se koriste za smanjenje temperature su alkalna i zemno alkalna jedinjenja poput natrijuma, kalijuma, barijuma i magnezijuma, koji su već u izvesnim količinama prisutni u glini, a povećavanjem njihovog sadržaja, dolazi do smanjenja maksimalne temperature pečenja. Industrija za proizvodnju opeke vrlo lako može da primeni različite aditive, jer je proces proizvodnje opeke vrlo jednostavan. Najčešće korišćen aditiv je soda-kreč-silicijum $\left(\mathrm{SiO}_{2}-\mathrm{Na}_{2} \mathrm{O}-\mathrm{CaO}\right)$ [3]. Zapravo, soda-kreč-silicijum je staklasti silikat generisan tokom procesa sazrevanja gline. Smanjivanje temperature sazrevanja opeke od gline predstavlja jaku indikaciju da dodavanjem sode-kreča-silicijuma u glinu dolazi do povećavanja efikasnosti u pečenju i zbog toga je vrlo bitna u cilju smanjenja potrošnje energije.

Kao aditiv, otpadno staklo, može da dovede do smanjenja procesa vitrifikacije u opekama od gline, rezultujući u visokoj gustini, manjoj apsorpciji vode i znatno manjem skupljanju prilikom sušenja. Međutim, neopodno je da se obrati pažnja i na osobine poput snage, poroznosti i skupljanja prilikom procesa pečenja.

\subsection{Potrošnja energije za mešavinu gline i stakla gde je njihov odnos 50:50}

Energetske uštede se posmatraju na dva načina: sa i bez gubitaka na zidovima peći. Procenat energije koji ulazi u peć se meri preko 4-20 mA kontrolnog signala. Zatim se uspostavlja korelacija između kontrolnog signala i stvarnog unosa energije u peć.

Sažeti rezultati istraživanja prikazanih u referenci [5] su sledeći:

Energija za pravljenje opeke od mešavine staklo/glina:

$>$ Uključujući peć - 8142 kJ

$>$ Bez gubitaka na peći - $1536 \mathrm{~kJ}$

Energija za pravljenje opeke od standardne mešavine:

$>$ Uključujući peć - 11695 kJ

$>$ Bez gubitaka na peći - $2513 \mathrm{~kJ}$

Procenat sačuvane energije:

$>$ Uključujući peć - $30.4 \%$

$>$ Samo opeka $-38.9 \%$

\subsection{Primer potrošnje energije na postorojenju za proizvodnju opeke u Grčkoj}

Fabrika za proizvodnju opeke u Grčkoj, koja je odabrana kao literaturni primer, proizvodi više tipova opeke. One se razlikuju u težini i dimenzijama. Prilikom standardnog procesa pečenja, energija koja se dobija od dizela je oko 5 $250960 \mathrm{~kJ}$. Tokom procesa oblikovanja gline, koristi se oko 1265616 kJ, a 658800 kJ se koristi tokom gnječenja gline. $352800 \mathrm{~kJ}$ se koristi za mlevenje i čišćenje, dok na proces sušenja odlazi $370800 \mathrm{~kJ}$ energije. Pečenje je energetski najzahtevnije. Korišćenjem naftnog koksa, potroši se oko $1673600000 \mathrm{~kJ}$. Takođe, potroši se oko 432000 kJ električne energije. Glavni izvor energije je naftni koks $(86.1 \%)$ u fabrici. Najveći deo toga odlazi na proces pečenja, a deo na gubitke u peći [2]. 


\subsection{Potencijalne energetske uštede prilikom upotrebe otpadne staklene ambalaže kao sekundarne sirovine u industriji građevinskog materijala u Vojvodini}

Iako gubici energije ne mogu biti svedeni na nulu, mogu se smanjiti na razne načine korišćenjem raznih tehnika, a pažljivim i efikasnim pristupom energija može da se troši u optimalnim količinama za odabrani proces.

Kad se ona koristi na neodgovarajući način, što znači da postoji razlika između dovedene količine energije i potrebne količine energije, to dovodi do rasipanja a time do finansijskog gubitka.

Neefikasno korišćenje energije mahom je rezultat lošeg projektovanja, neadekvatne radne karakteristike procesa, lošeg održavanja, praznog hoda ili rada opreme kada to nije potrebno.

Industrija građevinskog materijala godišnje proizvede oko $50 \quad 000 \quad 000 \mathrm{~kg}$ Giter bloka 25 (GB 25), na čiju proizvodnju se utroši:

> 3605 MWh električne energije, gde je $1 \mathrm{MWh}$ jednak $3600000 \mathrm{~kJ}$,

$>1993$ t naftnog koksa, gde je $1 \mathrm{t}$ jednaka 4184000 $\mathrm{kJ}$,

$>121000 \mathrm{Nm} 3$, gde se u Srbiji uzima vrednost od 33 $\mathrm{MJ} / \mathrm{m} 3$ pri pritisku od 1 bara i temperaturi od $00 \mathrm{C}$, te kada to konvertujemo u MJ a potom $\mathrm{u}$ kJ dolazimo do podataka od $3993000000 \mathrm{~kJ}$.

Na osnovu mnogobrojnih podataka iz literaturnih navoda, formule za izračunavanje potrebne toplote za podizanje temperature mešavine gline/stakla i standardne mešavine, sadržaja gline i stakla, toplotne moći goriva, udela stakla, godišnje produkcije fabrike, podataka iz literature da se mešavina gline i stakla peče skoro upola manje vremena nego obična mešavina, zatim podataka gde se potencijalna maksimalna ušteda energije u idealnom slučaju kreće od $30-40 \%$ za prirodni gas, a za naftni koks $15-25 \%$, podataka o različitim temperaturama pečenja i sušenja preuzetih takođe iz literature, kao i o različitom sadržaju nutrijenata u glini na osnovu lokacije iz koje se vadi poput kalionita, monmorionita, magnezijuma, kalcijuma i drugih, mogućnosti za modernizaciju postrojenja i unapređenja celokupnog procesa proizvodnje, dolazimo do potencijalnih energetskih ušteda u industiji Utrošen građevinskog materijala na teritoriji Vojvodine, (milijarde kJ) upotrebom otpadnog stakla kao sekundarne sirovine, koji su prikazani u Tabeli 2.

Tabela 2. Tabelarni prikaz potencijalnih energetskih ušteda $u$ industiji građevinskog materijala na teritoriji Vojvodine, upotrebom otpadnog stakla kao sekundarne sirovine

$\begin{array}{llll}\begin{array}{l}\text { Odnos } \\ \text { glina/stakla }\end{array} & \begin{array}{l}100 \% \\ \text { glina }\end{array} & \begin{array}{l}50: 50 \% \text { odnos } \\ \text { gline i stakla }\end{array} & \begin{array}{l}\text { 50:50 \% odnos } \\ \text { gline i stakla }\end{array} \\ \begin{array}{l}\text { Dominantna } \\ \text { vrsta goriva }\end{array} & \begin{array}{l}\text { Haftni } \\ \text { koks }\end{array} & \text { Naftni koks } & \text { Prirodni gas } \\ \begin{array}{l}\text { Toplotna moć } \\ \text { goriva }(\mathrm{kJ})\end{array} & \begin{array}{l}18000-31 \\ 000\end{array} & 18000-31000 & 35000-40000 \\ \begin{array}{l}\text { Tip proizvoda } \\ \text { Titer blok }\end{array} & \begin{array}{l}\text { Giter blok } 25 \\ \text { Godišnja }\end{array} & \text { Giter blok 25 } \\ \begin{array}{l}\text { produkcija } \\ \text { fabrike }(\mathrm{kg})\end{array} & \begin{array}{l}50000 \\ 000\end{array} & 60547500 & 66881700\end{array}$

Dnevna

produk
$(\mathrm{kg})$

\begin{tabular}{|c|c|c|c|c|c|}
\hline Komada po danu & 26838 & \multicolumn{2}{|l|}{32500} & \multicolumn{2}{|l|}{35900} \\
\hline $\begin{array}{l}\text { Temperatura } \\
\text { pečenja }\left({ }^{0} \mathrm{C}\right)\end{array}$ & 1150 & \multicolumn{2}{|l|}{1020} & \multicolumn{2}{|l|}{950} \\
\hline $\begin{array}{l}\text { Vreme potrebno } \\
\text { za postizanje } \\
\text { temperatura za } \\
\text { pečeњe (h) }\end{array}$ & 33 & \multicolumn{2}{|l|}{17.5} & \multicolumn{2}{|l|}{14.5} \\
\hline $\begin{array}{l}\text { Utrošena } \\
\text { sirovina }(\mathrm{kg})\end{array}$ & 9.2 glina & $\begin{array}{l}4.6 \\
\text { glina }\end{array}$ & $\begin{array}{l}4.6 \\
\text { otpadno } \\
\text { staklo }\end{array}$ & $\begin{array}{l}4.6 \\
\text { glina }\end{array}$ & \begin{tabular}{|l}
4.6 \\
otpadno \\
staklo
\end{tabular} \\
\hline $\begin{array}{l}\text { Težina gotovog } \\
\text { proizvoda (kg) }\end{array}$ & 6.9 & \multicolumn{2}{|l|}{6.9} & \multicolumn{2}{|l|}{6.9} \\
\hline $\begin{array}{l}\text { Dani } \\
\text { funkcionisanja } \\
\text { fabrike }\end{array}$ & 270 & \multicolumn{2}{|l|}{270} & \multicolumn{2}{|l|}{270} \\
\hline $\begin{array}{l}\text { Prosečna toplota } \\
\text { potrebna da se } \\
\text { podigne } \\
\text { temperatura } 1 \mathrm{t} \\
\text { proizvoda do } \\
\text { odgovarajućeg } \\
\text { nivoa }(\mathrm{kJ})\end{array}$ & 2008458 & \multicolumn{2}{|c|}{1559122} & \multicolumn{2}{|c|}{1156439} \\
\hline $\begin{array}{l}\text { Prosečna } \\
\text { energija potrebna } \\
\text { za pravljenje } \\
\text { proizvoda }(\mathrm{kJ})\end{array}$ & 2008 & \multicolumn{2}{|l|}{1559} & \multicolumn{2}{|l|}{1156} \\
\hline $\begin{array}{l}\text { Godišnja } \\
\text { potrošnja } \\
\text { električne } \\
\text { energije }(\mathrm{kJ})\end{array}$ & $\begin{array}{l}12987 \\
000000\end{array}$ & \multicolumn{2}{|c|}{8700000000} & \multicolumn{2}{|c|}{6498000000} \\
\hline $\begin{array}{l}\text { Godišnja } \\
\text { potrošnja } \\
\text { naftnog koksa } \\
(\mathrm{kJ})\end{array}$ & $\begin{array}{l}83442 \\
924000\end{array}$ & \multicolumn{2}{|c|}{66223111556} & \multicolumn{2}{|c|}{1242920} \\
\hline $\begin{array}{l}\text { Godišnja } \\
\text { potrošnja } \\
\text { prirodnog gasa } \\
(\mathrm{kJ})\end{array}$ & $\begin{array}{l}3993000 \\
000\end{array}$ & \multicolumn{2}{|c|}{3033000000} & \multicolumn{2}{|c|}{51322711456} \\
\hline
\end{tabular}

Производња Гитер блока 25

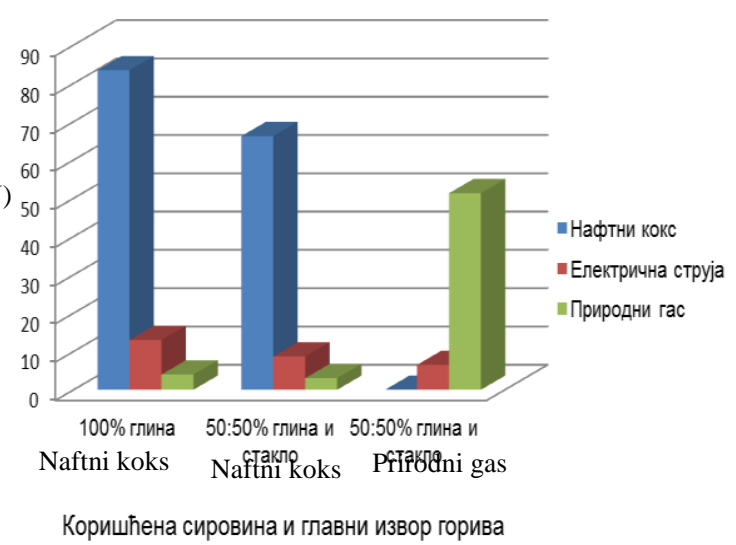

Slika 1. Grafički prikaz prikaz potencijalnih energetskih ušteda u industiji građevinskog materijala na teritoriji Vojvodine, upotrebom otpadnog stakla kao sekundarne sirovine

\section{ZAKLJUČAK}

Industrija opeke predstavlja jednog od najznačajnijih potrošača energije, ali i najbolji primer kako i na koji način ostvariti potencijalne energetske uštede. Mnoga 
istraživanja jasno pokazuju da kombinacija opeke i otpadnog stakla predstavlja veliki potencijal $\mathrm{u}$ datoj industriji, kako sa aspekta uštede sirovina, tako i sa aspekta energetskih ušteda. Njihovo kombinovanje, prema trenutno dostupnim literaturnim podacima, može se ostvariti do nivoa gde se $50 \%$ gline zameni sa otpadnim staklom. U većini slučajeva, glavni problem za direktnu primenu predloženih postupaka, predstavlja zastarelost samih peći, neadekvatno gorivo, proces pečenja a potom i neadekvatno iskorišćenje otpadnog stakla.

Prvi i osnovni korak bi trebalo da bude modernizacija samih postrojenja, odnosno peći za pečenje, na čijim zidovima se gubi ogromna količina energije pa samim tim raste potrošnja energenata koji se koriste. Standardni proces pečenja koristi sirovinu sastojanu samo od gline, predstavlja neodrživ proces, što znači da, kombinovanjem gline i stakla u velikoj meri redukuje potrošnja energenata, smanjuje dužina trajanja procesa, obezbeđuje kvalitetnija opeku i proizvodi od keramike. Bitno je napomenuti da odnos glina/staklo zavisi i od kvaliteta same gline, pa će u zavisnosti od toga i maseni udeo staklo/glina se razlikovati od ciglane do ciglane. U datim postrojenjima se u većini slučajeva koristi ekološki neprihvatljivo gorivo poput naftnog koksa i dizela, koji svojim sagorevanjem negativno utiču na životnu sredinu. Gorivo koje se najbolje pokazalo, očekivano, jeste prirodni gas, čija se količina znatno smanjuje kada se deo gline zameni sa otpadnim staklom, a sve zbog bržeg vezivanja sirovina i efikasnijeg dostizanja neophodne gustine.. Da bi se značajno smanjila potrošnja energije, neophodno je da zamena gline kao osnovne sirovine bude u masenom opsegu od 40-50\%, kako bi se postigli najbolji rezultati.

\section{LITERATURA}

[1] Kirby R, 2006. Potential Energy Savings From the Use of Recycled Glass in Brick Manufacturing, California Department of Conservation - Division of Recycling, California.
[2] Koroneos C, Dompros A, 2006. Environmental assessment of brick production in Greece, Thessaloniki, Greece.

[3] Phonphuak N, Kanyakam S, Chindaprasirt P, 2015. Utilization of waste glass to enhance physicalemechanical properties of fired clay brick, Khon Kaen University, Thailand.

[4] Raimondo M, Zanelli C, Matteucci F,Guarini G, Dondi M, Labrincha J.A, 2006. Effect of waste glass (TV/PC cathodic tube and screen) on technological properties and sintering behaviour of porcelain stoneware tiles, CNR-Institute of Science and Technology for Ceramics, Faenza.

[5] Tyrell M.E amd Goode A.H, 1972: Waste Glass as a Flux for Brick Clays; Report of Investigations 7701n Bureau of Mines, Tuscalosa.

\section{Kratka biografija:}

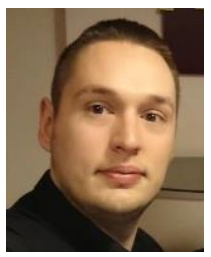

Milan Trbulin rođen je u Apatinu. Na Fakultetı tehničkih nauka diplomirao je 2014, a master rac na Fakultetu tehničkih nauka iz oblasti Inženjerstva zaštite životne sredine odbranio je 2019.god.

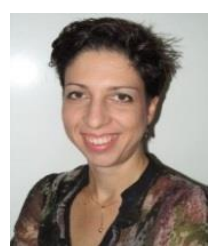

Dr Dragana Štrbac, vanredni profesor na Fakultetu tehničkih nauka u Novom Sadu, na Katedri za Inženjerstvo zaštite životne sredine. Koautor je 24 rada sa SCI liste i 74 drugih radova i saopštenja. 